\title{
Programming with Tabling in XSB
}

\section{(Invited Lecture)}

\author{
D.S. Warren \\ Computer Science \\ State University of NY at Stony Brook \\ Stony Brook, NY 11794-4400 USA \\ warren@CS.SunySB.edu
}

\begin{abstract}
I describe how XSB, a tabling Prolog system, can be used effectively to program useful tasks in a variety of domains. The presentation is through the use of examples, with examples being taken from some of the following areas: traditional dynamic programming problems, finite state automata theory, context-free language recognition, parsing and analysis, recursive aggregation, meta-interpreters, program analysis and abstract interpretation, model checking, and abduction.
\end{abstract}

Program analysis and model checking will be emphasized.

\section{BIOGRAPHY}

David Scott Warren received his $\mathrm{PhD}$ in Computer Science from the University of Michigan in 1979. He then joined the faculty at the University at Stony Brook where he is currently Professor of Computer Science and chair of the Computer Science Department. For the past fifteen years his research has centered around a variety of topics in the area of logic programming. He has more than 60 publications, is co-author of a major book in the area, and has advised 16 students who have completed their $\mathrm{PhD}$ degrees. He has been a leading Principal Investigator of three major multi-million dollar institutional infrastructure grants from NSF and numerous smaller grants. Professor Warren has been active in the logic programming community, serving on many conference program committees. He is the Past President of the Association for Logic Programming, an international professional organization of approximately 1000 members. 